\title{
Ocorrências de anáforas encapsuladoras em redações do Enem
}

\section{Occurences of encapsulating anaphors in Enem essays}

\author{
Roberlei Alves Bertucci* \\ Universidade Tecnológica Federal do Paraná, Curitiba, PR, Brasil \\ Andréa Jacqueline Malheiros ${ }^{* *}$ \\ Universidade Tecnológica Federal do Paraná, Curitiba, PR, Brasil \\ Wanderlei de Souza Lopes ${ }^{* * *}$ \\ Universidade Tecnológica Federal do Paraná, Curitiba, PR, Brasil
}

\begin{abstract}
Resumo: Este trabalho pretende verificar como as anáforas encapsuladoras também conhecidas como encapsulamentos - são utilizadas como rótulos avaliativos no gênero redação do Enem. Primeiramente, destacamos a importância da referenciação pelas anáforas, por serem um meio relevante para a coesão textual. Depois, ressaltamos o papel dos encapsulamentos em sumarizar e rotular porções textuais, construindo objetos de discurso essenciais para a coesão e, no caso dos textos argumentativos, para o posicionamento do autor (Conte, 2003; Koch, 2004a; Cavalcante, 2005; Bertucci, 2006). Nosso corpus é constituído de 31 redações nota 1000 no Enem de 2018. Após a seleção, quantificamos a ocorrência das anáforas encapsuladoras, distinguindo-as entre descritivas e opinativas. Verificamos que: i) apenas 2 redações não apresentavam os encapsulamentos sob análise; ii) houve uma ocorrência maior do tipo descritivo (79\%); e iii) em apenas dois textos o tipo opinativo se sobressaiu. Do ponto de vista qualitativo, decidimos analisar dois casos. Em ambos, a análise corrobora a ideia de que essas anáforas são essenciais para a coesão do texto e, no caso do gênero redação do Enem, são essenciais também para o direcionamento argumentativo do texto. Não à toa, foram avaliados com a nota máxima no Exame.
\end{abstract}

Palavras-chave: Anáfora. Encapsulamento. Redação. Enem.

\begin{abstract}
This paper aims to verify how encapsulating anaphors - also known as encapsulations - are used as evaluative labels in the genre Enem essay. Firstly, we underline the relevance of anaphors for referential processes, since they contribute to the textual cohesion. Secondly, we reinforce the role of anaphoric encapsulation in both summarizing and labeling textual portions, which builds discourse objects used in cohesion and, in the case of argumentative texts, in benefit to the author's point of view (Conte, 2003; Koch, 2004a; Cavalcante, 2005; Bertucci, 2006). The corpus consists in 31 essays graded to 1000 points, the maximal score. After selection, we quantified the anaphors, by distinguishing them in descriptive or argumentative ones. We verify that: i) only 2 essays had no encapsulating anaphors; ii) descriptive encapsulating anaphors are more frequent (79\%); iii) only 2 essays
\end{abstract}

* Professor Doutor, Departamento Acadêmico de Linguagem e Comunicação, Universidade Tecnológica Federal do Paraná, Curitiba, PR, Brasil; bertucci@utfpr.edu.br

** Graduanda em Letras Português, Universidade Tecnológica Federal do Paraná, Curitiba, PR, Brasil; andreajmalheiros@gmail.com

*** Graduando em Letras Português, Universidade Tecnológica Federal do Paraná, Curitiba, PR, Brasil; wandersl@yahoo.com.br 


\begin{abstract}
had more argumentative encapsulating anaphors. From a qualitative perspective, we analyzed two essays. In both, the analyses corroborate to the comprehension that these anaphors are essentials to textual cohesion and, in the case of the genre Enem essay, they are also essential to the author's point of view about the theme. Then, it is not by chance that they have got the maximal score in the national Exam.
\end{abstract}

Keywords: Anaphors. Encapsulations. Essay. Enem.

\title{
1 INTRODUÇÃo
}

É sempre um enorme desafio se trabalhar com a argumentação, já que, sendo um processo que envolve inúmeros elementos textuais e contextuais, requer do pesquisador um recorte adequado do objeto. No caso de produções textuais, escolher elementos linguísticos que possam contribuir para a construção argumentativa pode ser uma saída interessante. É o caso das anáforas. Na literatura, entende-se que elas contribuem para a progressão textual, à medida que fazem o movimento de retomada de elementos no texto. No entanto, defende-se que essa retomada é que constrói os elementos discursivos, que não são dados a priori, mas são constituídos pelo próprio autor na tessitura da escrita. Por isso, as anáforas podem ser decisivas para a força argumentativa, já que, não só levam a uma progressão do texto, como indicam o modo como essa progressão se dá e os objetos que o autor constrói na retomada.

Nesse sentido, as redações do Exame Nacional do Ensino Médio (Enem) parecem ser uma fonte interessante de estudo de argumentação: ali, além da exposição, discussão e análise de um tema, é necessário articular informações de áreas diversas com coesão e coerência. Por isso, nessas produções, as anáforas devem merecer uma atenção especial de professores e pesquisadores. Ademais, o Exame, em si, além de apontar aspectos de formação linguística dos estudantes concluintes do ensino básico, é uma porta de entrada ao ensino superior (nacional e internacional). ${ }^{1}$ Nesse sentido, identificar o modo como as anáforas são utilizadas em um texto é o primeiro passo para se entender a formação básica do estudante, bem como seu domínio linguístico em torno da argumentação.

Infelizmente, dados divulgados pelo Instituto Nacional de Estudos e Pesquisas Educacionais Anísio Teixeira (Inep) mostram que aumentou em mais de 20\% o índice das notas consideradas baixas - até 400 pontos - em redação no Exame Nacional do Ensino Médio (Enem) 2018, comparado ao ano anterior ${ }^{2}$. Como se sabe, o processo de escrita de um texto no formato dissertativo-argumentativo exige que "o candidato deva conhecer forma e conteúdo desse tipo de composição" (Salvador, 2013, p. 27), de modo que o raciocínio criado por ele convença o leitor sobre um determinado questionamento da realidade. Assim, pesquisas voltadas a essa finalidade se fazem necessárias na Linguística Textual, como salienta Cavalcante (2005, p. 125): "é da interrelação entre língua e práticas sociais que emergem os referentes." E é dessa interrelação que pode sair uma avaliação mais global da formação e da habilidade de produção dos candidatos.

\footnotetext{
${ }^{1}$ Disponível em: < http://portal.inep.gov.br/enem/enem-portugal> Acesso em 11. Mar. 2020.

2 Disponível em: < https://vestibular.brasilescola.uol.com.br/enem/enem-2018-redacoes-com-notasconsideradas-baixas-aumentam-mais/344577.html>. Acesso em: 04/mai/2019.
} 
Além disso, estudos em linguística mostram que o processo de referência vai além do emprego de conectividade e retomada de ideias, e que referência e anáfora não são "termos intercambiáveis" (Cavalcante, 2005, p. 126). A referência, de modo geral, pode ser entendida como a forma de designar objetos de discurso (referentes) em um texto. Por isso, a anáfora é um processo essencial, já que recupera um referente específico no texto, garantindo a sequencialidade do texto (Koch; Marcuschi, 1998) ${ }^{3}$. Focaremos, neste trabalho, as anáforas complexas, denominadas encapsuladoras, assumindo que são um tipo de expressão referencial que recupera uma parte do texto (ou do discurso). Ao mesmo tempo, defendemos que elas não são uma retomada simples de parte do texto, nem são meramente descritivas, mas carregam uma força subjetiva enorme. Assumimos, assim, a posição de Conte (2003, p. 179), para quem "o encapsulamento anafórico é um recurso coesivo muito importante (especialmente em textos argumentativos escritos) e não tem recebido consideração tão suficiente quanto mereceria na discussão dos processos anafóricos." Acrescentamos, no entanto, que essa atenção ao fenômeno também não ocorre na escola ou nos materiais de ensino. Mesmo assim, nossa intenção é observar sua ocorrência em redações nota 1000 do Enem, para atestar se (e como) falantes reconhecidamente proficientes na escrita desse gênero argumentativo usam os encapsulamentos.

No Enem, é essencial que se desenvolva uma redação com uso de repertório variado e argumentação bem articulada. No entanto, isso tudo exige o uso de mecanismos linguísticos específicos, capazes de mostrar o domínio do candidato sobre o processo de escrita da argumentação. No Exame, há, inclusive, um critério especial de avaliação desses mecanismos (Competência IV), que envolve não só o uso de operadores argumentativos, como de recursos anafóricos. Por isso, poderíamos perguntar: qual é a importância das anáforas encapsuladoras nos textos do Enem?

Ao estudar o fenômeno em redações do Enem, pretende-se também descrever o papel das anáforas encapsuladoras nesse gênero. Essa questão é válida ao se considerar que o processo de encapsular pode ser carregado de uma visão bastante subjetiva do autor do texto, conforme apontam estudos anteriores. Nesse sentido, assumimos que o uso desse tipo de anáfora favorece a formulação de uma avaliação, por parte do autor, sobre as proposições retomadas. Como se verá adiante, o uso de encapsulamentos essencialmente opinativos é um recurso muito interessante para se expressar o ponto de vista em textos de estrutura impessoal, ${ }^{4}$ como as redações nota 1000 do Enem.

Com bases nessas propostas, o presente artigo tem um objetivo duplo: descrever a ocorrência das anáforas encapsuladoras em textos do Enem e verificar em que medida elas são utilizadas como rótulos avaliativos, contribuindo para a construção argumentativa que esse gênero exige do candidato. Para isso, selecionamos um corpus de 31 redações nota 1000 no Enem de 2018, disponibilizado pelos próprios participantes em uma cartilha de acesso livre (detalhes na Metodologia).

\footnotetext{
${ }^{3} \mathrm{O}$ verbo recuperar indica a existência de um referente presente previamente no texto. E, apesar de assumirmos que tais objetos referenciais só são construídos no discurso, na materialidade do texto, entendemos que recuperar mantém viva a ideia de retomada e sequencialidade essencial às anáforas.

${ }^{4}$ Garcez (2017b) afirma que o uso de terceira pessoa é preferencial. No entanto, Pereira (2018) observou que as redações nota 1000 são todas construídas na terceira pessoa, o que parece caracterizar uma obrigatoriedade e não uma preferência.
} 
O trabalho está organizado assim: iniciaremos por discutir encapsulamento, apresentando também algumas pesquisas sobre o tema em textos argumentativos; depois, trataremos das características da redação do Enem; finalmente, apresentaremos a metodologia e a análise do corpus selecionado.

\section{ANÁFORA ENCAPSULADORA}

Os processos anafóricos fazem parte de uma característica importante da linguagem, que é a capacidade de referenciar. Para Koch e Elias (2017), a referenciação é atividade discursiva, isto é, na prática de interação verbal, o sujeito, dentro do seu contexto político-social, seleciona os recursos linguísticos disponíveis para se expressar com outro, "em função de um querer dizer" (Koch; Elias, 2017, p. 124). Se é assim, pode-se considerar uma instabilidade na relação entre as palavras e as coisas (Koch, 2004b) e, também, entre os objetos discursivos construídos no texto e seus possíveis correferentes textuais. Para tanto, na sequenciação, o autor constrói objetos de discurso para que sejam referenciados ao longo do texto, o que permite progressão por coesão. Koch (2004b) ressalta esse caráter discursivo do processo de referenciação, já que as entidades ali referenciadas têm uma relação discursiva com o texto, não uma dimensão extensional com o mundo. Nesse sentido, o processo anafórico é essencial para que a referenciação se estabeleça e para que a prática linguística atinja seus objetivos naquele texto.

No geral, as anáforas se dividem em dois grupos: diretas e indiretas. Designamse por anáforas diretas os grupos ou termos nominais com a função de retomar elementos já presentes no texto, condicionando assim, a progressão textual. Vejamos o exemplo (1).

(1) Um menino apareceu na porta; o garoto perguntou pela irmã.

Aqui, percebemos que um menino e o garoto são expressões correferencias e diretas, porque se referem ao mesmo elemento, com a diferença de que uma expressão introduz um elemento novo (um menino) e a outra, o conhecido (o garoto). De qualquer modo, podemos dizer que $o$ garoto recupera totalmente seu referente inicial, de forma direta.

Por seu turno, fundamentam-se as indiretas pela ausência de um termo explícito antecedente. No mesmo exemplo (1), a introdução de a irmã é feita com o artigo definido, que pressupõe um referente já conhecido na interação. Por outro lado, nenhuma menina fora introduzida ali e, apesar disso, o falante não tem dificuldades em interpretar o trecho, porque parte do conhecimento de mundo sobre relações entre as pessoas (nesse caso, relação de irmandade). Logo, a referência é indireta, buscada pela relação do referente introduzido antes (menino), sendo uma recuperação parcial no co(n)texto.

Nesse ponto reside a complexidade dos encapsulamentos, já que podem ser considerados de natureza híbrida (direta/indireta). Linguisticamente, são geralmente tomados como formas nominais capazes de recategorizar, recuperar ou sumarizar segmentos textuais, com o intuito de rotulá-los (Conte, 2003; Apothéloz, 2003; Koch, 2004a; 2005; Cavalcante, 2003b). A definição de Cavalcante (2003b, p. 115) sobre o fenômeno lança luz à questão: "encapsular consiste em resumir proposições do discurso empacotando-as numa expressão referencial, que pode ser um sintagma 
nominal (...), ou pode ser um pronome, geralmente demonstrativo." Cavalcante (2003b) lembra que o sintagma nominal pode receber o nome de "rótulo", conforme proposto por Francis (1994).

Koch (2004b, p. 66) acrescenta que essa rotulação "designa um fenômeno geral de transformação de proposições em entidades (...)". Para a autora, outra característica importante do fenômeno é o fato de, dentre tantas possibilidades de se rotular partes do discurso, a escolha feita pelo produtor é muito relevante, porque indica como ele interpreta o mundo. Além disso, Koch (2004b) defende que a interpretação dessas anáforas exige muito esforço do receptor, exatamente pela complexidade que carrega.

Por isso, como afirma Cavalcante (2003b, p. 116), "temos que admitir que, à semelhança de uma anáfora direta, os encapsuladores recuperam (sem retomar) o que há no co(n)texto." Isso significa que levam o leitor àquilo que está presente anteriormente no texto, mas também são capazes de rotular de forma particular o que é recuperado, sem que seja uma simples relação de paráfrase, por exemplo. Nesse sentido, Apothéloz (2003, p. 72) considera que essa retomada pode ser a oportunidade de o falante "manifestar a sua subjetividade ou repetir a de outrem." Podemos entender essa posição do autor como uma consequência da própria noção de encapsulamento: sendo este um rotulador de um segmento discursivo, nunca é neutro ou vazio, porque as escolhas linguísticas dos falantes nunca o são. Sobre isso, tomemos o exemplo em (2).

(2) O Pedro saiu do trabalho e foi ao futebol sem avisar. Essa atitude deixou a Maria furiosa.

No exemplo, essa atitude tem função de encapsulamento, porque congrega uma parte grande do discurso apresentado no trecho imediatamente precedente. Ali, pode retomar totalmente as três ações de Pedro ou recuperar apenas algumas delas (como a falta de aviso). Essa variabilidade no trecho encapsulado vai ao encontro da afirmação de Koch (2004b, p. 59) de que "a interpretação de uma expressão anafórica consiste não em localizar um segmento linguístico ('antecedente') ou um objeto específico no mundo, mas em estabelecer uma relação com algum tipo de informação presente na memória discursiva."

Se é assim, podemos considerar que os encapsulamentos contribuem também para uma discussão sobre processos inferenciais, porque podem recuperar total ou parcialmente elementos do co(n)texto, mas exigem do leitor que encontre uma relação de inferência entre o rótulo o trecho do discurso encapsulado. Ademais, no exemplo em (2), o sintagma nominal essa atitude rotula alguma parte do segmento anterior e, como se disse, manifesta uma subjetividade do autor. Dito de outra maneira, além de condensar um trecho por meio de retomada, apresenta ao leitor/ouvinte as opiniões e crenças do produtor do texto. Desse modo, trata-se de uma ferramenta de auxílio no processo de construção do sentido, em especial em textos argumentativos.

$\mathrm{O}$ aspecto rotulador e indireto dos encapsulamentos liga-se à noção nãoextensional de referenciação proposta por Koch (2004b). Para a autora, à medida que entendemos esse processo como discursivo, podemos postular que "nosso cérebro não opera como um sistema de espelhamento, ou seja, nossa maneira de ver e dizer o real não coincide com o real.” (Koch, 2004b, p. 57). Portanto, à medida que podemos construir objetos de discurso complexos e referenciá-los com encapsulamentos, reforçamos essa noção de que as referências são feitas a partir de objetos construídos no discurso e não necessariamente com aqueles encontrados diretamente no mundo. 
Acrescentamos que, para Mondada e Dubois (2003, p. 33), "uma categoria lexical impõe um ponto de vista", que pode ser aceito, contestado ou negociado entre os falantes. Na mesma direção, Apothéloz (2003, p. 71-72) afirma que esse tipo de anáfora pode ser a oportunidade de o falante "manifestar a sua subjetividade ou repetir a de outrem." Koch (2004b) defende que, à semelhança de outras formas de referenciação, os encapsulamentos revelam um posicionamento do produtor no contexto. Por isso, a rotulação não é gratuita e, como todo processo referencial, é ancorada no discurso. De modo mais enfático, Koch (2004a, p. 255-256) afirma que as anáforas encapsuladoras podem rotular um segmento do texto tanto com a função básica de transformá-lo num objeto-de-discurso e, consequentemente, favorecer a progressão textual, quanto ser um "rótulo avaliativo (...), com o poder de orientar o interlocutor no sentido de determinadas conclusões".

Sendo assim, vamos considerar que elas podem ser utilizadas basicamente de dois modos: primeiro, como essencialmente descritivas, quando nomeiam seu referente com um nome ou característica geral, quase sempre com aspectos inferenciais relacionados. Um exemplo disso é o contexto em (2), em que atitude é uma palavra que caracteriza as ações que Pedro realizou. Ainda que a escolha por esse substantivo tenha sido consciente, não se pode dizer que seja uma opinião, um argumento (favorável ou contrário) à atitude de Pedro. Segundo, consideraremos as anáforas encapsuladoras como essencialmente opinativas, quando esse nome ou característica tiver traços do ponto de vista do autor. Para exemplificar, imagine que (2) fosse reescrita em (3).

(3) O Pedro saiu do trabalho e foi ao futebol sem avisar. Essa estupidez deixou a Maria furiosa.

Nesse caso, o sintagma essa estupidez parece revelar menos uma descrição a respeito da atitude de Pedro e mais uma opinião incisiva do autor. Assim, enquanto em (2) atitude parece ser uma palavra geral para rotular o que Pedro fez, sendo, portanto, predominantemente descritiva, em (3), estupidez é núcleo de uma anáfora essencialmente opinativa, manifestando o ponto de vista do sujeito sobre o fato.

Tendo em vista o gênero de texto que analisaremos (dissertativoargumentativos), temos a intenção de verificar se esse caráter opinativo é recorrente no uso de encapsulamentos. Assim como observou Bertucci (2006), em textos de opinião (argumentativos), "avaliar é parte da construção textual"; se os encapsulamentos favorecem essa tarefa, é um recurso importante a ser observado nas redações. Tal análise pode contribuir para a compreensão das características do gênero, bem como destacar a importância desse processo anafórico no ensino regular.

Na literatura (Conte, 2003; Cavalcante, 2003b; Koch, 2004a), destaca-se que as anáforas encapsuladoras, além de serem construídas por sintagmas nominais, em geral, são introduzidas por pronomes demonstrativos, tal como nos exemplos (2) e (3). Outro ponto fundamental é que, por vezes, o pronome isso pode ser o único integrante do sintagma, encapsulando um trecho do discurso - o leitor pode fazer o teste, substituindo os encapsulamentos em (2) e (3) por isso. Em geral, a recuperação de conteúdo com esse pronome é bastante complexa (Bertucci, 2006) e não será tratada neste trabalho. Por vezes, o advérbio tal também pode funcionar como introdutor de sintagmas encapsuladores. Em (2), poderíamos ter tal atitude deixou a Maria furiosa.

Destaca-se também que, de acordo com Apothéloz (2003), se o referente tiver o mesmo núcleo do sintagma nominal, não se tem um caso de encapsulamento, mas 
de anáfora fiel (Apothéloz, 2003, p. 71). Isso ocorreria em (2) e (3), por exemplo, se tivéssemos esse futebol deixa a Maria furiosa, em que futebol é o núcleo do sintagma, mas já fora referido anteriormente. Assim, para os critérios desse trabalho, não serão considerados encapsulamentos os casos de repetição lexical do núcleo da anáfora encapsuladora e seu referente.

Destacamos, por fim, a função metadiscursiva dos encapsulamentos. Koch (2005) afirma que é comum, no processo de referenciação por essa estratégia, que os objetos de discurso construídos sejam partes da própria enunciação. Assim, estruturas como essa opinião ou esse comentário encapsulam trechos do discurso, mas os caracterizam metadiscursivamente. Bertucci (2006) encontrou essa estratégia em textos de opinião em jornal, mas, em nosso trabalho, não vamos checar essa função nas redações do Enem.

Assim, olhando para os pontos indicados acima, uma pergunta que surge é: os possíveis encapsulamentos presentes nas redações do Enem são essencialmente descritivos ou essencialmente opinativos?

Trabalhos anteriores tentaram averiguar o papel desses elementos em textos de opinião. Bertucci (2006) apresenta algumas características das anáforas encapsuladoras em alguns textos retirados da seção Opinião do jornal Folha de São Paulo. À luz dessas análises, procura responder qual a importância dessas anáforas em textos de opinião. A conclusão principal do autor é que os encapsulamentos trazem um conteúdo avaliativo em que se expõe a opinião do autor ou de terceiros. Do ponto de vista argumentativo, portanto, são um modo de se posicionar em relação ao tema, sobretudo quando trata de fenômenos abstratos, cujos objetos de discurso precisam ser construídos de forma menos extensional.

Por outro lado, Cordeiro (2006) analisou 60 redações escolares dissertativas produzidas por turmas do $3^{\circ}$ ano do ensino médio. A autora destaca que os encapsulamentos, quando usados corretamente, têm mais força argumentativa se utilizados no início do parágrafo, porque recuperam mais facilmente a informação encapsulada. ${ }^{5}$ Em contrapartida, Cordeiro (2006) afirma que o uso inadequado das anáforas encapsuladoras exige do leitor maior esforço de interpretação, o que prejudica a força argumentativa do texto. Por isso, a autora realça a importância das anáforas encapsuladoras no processo de organização de ideias e como junção semântica na cadeia global do texto com o intuito de manter a logicidade e conduzir o leitor para aderir ao ponto de vista do autor. Ademais, a autora enaltece o conteúdo das anáforas encapsuladoras concluindo que acredita ser obrigatória a promoção desse conteúdo nos currículos escolares.

Tendo em vista os trabalhos supracitados, ressaltamos os encapsulamentos como um caso sui generis de anáforas. Diferentemente dos autores citados, porém, o corpus analisado no presente estudo situa-se a meio caminho entre os que serviram de base para os trabalhos deles. Isto é, enquanto Bertucci (2006) analisou corpus de jornal, o que pressupõe um amplo domínio de repertório linguístico, Cordeiro (2006) verificou a produção específica de alunos do terceiro ano do ensino médio. Nesta

\footnotetext{
5 Para Conte (2003) e Koch (2004b), o fato de os encapsulamentos introduzirem referentes novos permite que sirvam de tema para a estrutura discursiva, razão pela qual aparecem frequentemente em posição inicial de parágrafo. Conte (2003, p. 184) acrescenta ainda que, estando no início de "um novo parágrafo, o encapsulamento anafórico é a sumarização imaginável mais curta de uma porção discursiva precedente."
} 
pesquisa, nós nos deteremos sobre redações, o que nos aproxima do corpus de Cordeiro, pelo caráter escolar. Mas, serão redações nota mil do Enem, o que nos aproxima do corpus de Bertucci, pelo caráter de excelência dos textos. Mais especificamente, analisaremos 31 (trinta e uma) redações disponibilizadas pelos próprios candidatos em compilação própria deles. Posto isso, entre as perguntas que esperamos responder estão: 1) Os autores desses textos utilizam encapsulamentos? Se sim, com qual frequência? 2) Eles utilizam encapsulamentos com caráter mais descritivo ou mais opinativo? Assim, esperamos contribuir tanto para a análise do gênero textual em questão quanto para a importância do tópico nos estudos sobre os encapsulamentos.

\section{A REDAÇÃO DO ENEM}

Antunes (2016) destaca que o mundo letrado em que vivemos exige das pessoas práticas de leitura e escrita em diferentes contextos, cabendo à escola um papel de protagonismo no ensino de tais práticas, a fim de contribuir para a autonomia dos cidadãos. Nesse contexto, o ensino de gêneros textuais diversos deve materializar essas práticas e preparar o estudante para o mundo em que vive.

A produção textual, em especial no ambiente escolar, deve ser entendida como uma atividade extremamente complexa. Primeiro, por exigir um foco em diferentes pontos envolvidos no ato de escrever, como o conteúdo, a finalidade e o modo de o fazer (Antunes, 2016). Depois, o estabelecimento de critérios claros para o estudante é um desafio, já que devem ser estipulados levando em conta toda a variação e especificidade que cada gênero exige (Santos; Teixeira, 2016).

Para Val (2017), a redação clássica, que tinha como base apenas uma frase ou palavra-tema dificultava o desenvolvimento de habilidades de escrita dos alunos, porque focava muito no conteúdo (o que ele sabia sobre o tema) e na forma (se estava de acordo com a norma padrão). Por outro lado, podemos considerar que a redação do Enem, ainda que com características desse modelo clássico de redação - ter um tema cujo conteúdo deve ser amplamente desenvolvido -, é diferente por pelo menos duas razões: primeiro, por apresentar diferentes textos motivadores, que contribuem com a busca de um repertório amplo sobre o tema; depois, por estabelecer critérios de construção e avaliação que podem ser ensinados e praticados (Garcez, 2017b). Ressalta-se ainda o contexto do Exame: sendo uma prova de abrangência nacional e uma forma de ingresso no ensino superior nacional (e internacional), a redação parece cumprir um papel importante para a avaliação das habilidades de escrita dos candidatos. $^{6}$

Nesse sentido, a complexidade exigida na produção de um texto vai além da capacidade do produtor de apresentar um conteúdo com coesão e coerência. Como discorre Garcez (2017b, p. 275),

a produção de um texto é uma atividade complexa que exige simultaneamente competências compostas de muitas habilidades cognitivas: concentração, planejamento, seleção, hierarquização,

\footnotetext{
${ }^{6}$ Cançado et al. (2020) questionam a eficiência de avaliações como a do Enem, em especial pela subjetividade da correção, mesmo com critérios estabelecidos. Deixamos essa questão de lado, por não ser foco do trabalho, mas sugerimos o texto aos leitores interessados no tema.
} 


\begin{abstract}
comparação, abstração, síntese, generalização, atenção controlada, ou seja, as funções superiores da mente de que nos fala Vygotsky. Essas habilidades são desenvolvidas na experiência cotidiana e em todo o processo educacional escolar em várias áreas, e não apenas nas atividades de língua portuguesa, mas principalmente na leitura. No Exame Nacional do Ensino Médio (Enem), a redação demonstra o nível de desenvolvimento dessas habilidades aplicadas à produção de um texto.
\end{abstract}

Levando em conta todas essas questões, podemos assumir que as redações com nota máxima no Exame indicam autores com excelente nível de desenvolvimento das habilidades apontadas por Garcez. Logo, o estudo desses textos contribui não só para o entendimento de questões linguísticas ali envolvidas como também para a reflexão dos processos de ensino de produção textual. Nesse sentido, a escrita da redação do Enem deve ser precedida, em especial no ambiente escolar, por escritas de outros gêneros que contribuam para o desenvolvimento de habilidades diversas e sempre com critérios claros, conforme defendem Santos e Teixeira (2016). ${ }^{7}$

Para um bom percurso de escrita de textos, a leitura o planejamento e a reescrita são pontos fundamentais. Primeiro, não se pode escrever sobre o que não se conhece ou sobre o que pouco se conhece (Antunes, 2016). A diversidade de fontes e pontos de vista contribui para o desenvolvimento de habilidades cognitivas essenciais no processo de amadurecimento da escrita. Depois, o planejamento é imprescindível para ato da escrita, porque, conforme defende Travaglia (2016), planejar é orientar o percurso discursivo-linguístico de um texto a partir dos critérios estabelecidos. Por fim, a reescrita é um modo de entender que nenhum texto nasce pronto; ao contrário, é na reescrita que o percurso planejado é melhor alcançado, já que os critérios são revistos e a escrita, repensada. Reescrever, portanto, não é higienizar o texto, mas refletir sobre a capacidade dele de atingir seu objetivo a partir dos critérios estabelecidos. É, portanto, parte imprescindível no processo de escrita.

Para que tudo isso seja alcançado numa redação nota 1000 do Enem, o candidato deve entender uma série de aspectos linguísticos do gênero solicitado. Entre eles, está a natureza híbrida dessa produção, já que parece condensar dois tipos textuais: o dissertativo e o argumentativo. Ao tratar dos tipos textuais e a relação deles com a redação modelo Enem, Garcez (2017a, p. 45) ressalta que eles "se definem pela natureza linguística intrínseca de sua composição. As escolhas lexicais, os aspectos sintáticos, o emprego de tempos verbais, as relações lógicas estabelecidas definem o tipo textual." No entanto, é preciso dizer que o tipo argumentativo é bastante complexo. Coroa (2017), ao comparar a possibilidade de caracterização dos tipos, na mesma perspectiva do texto estilo Enem, sustenta que as características de organização textual são de difícil identificação para o tipo argumentativo, embora recorra "com muita frequência às relações lógicas para demonstrar a verdade daquilo que diz, como as de causa e consequência e as de condição." (Coroa, 2017, p. 61). A autora defende ainda que essas relações se apresentam por conectivos e que a seleção lexical também tem um papel decisivo no objetivo argumentativo de cada texto.

Como se vê, são indicados aqui aspectos importantes para a caracterização do tipo argumentativo no texto do Enem, em especial, o cuidado com as relações lógicas e a seleção lexical - esta última pode indicar o repertório do candidato (Pereira, 2018;

\footnotetext{
${ }^{7}$ Garcez (2017b) oferece aos leitores, em especial aos professores, algumas sugestões de como se pode desenvolver cada uma das cinco competências exigidas no Enem.
} 
Silva, 2018). Entre tais aspectos, levantamos a hipótese de que as anáforas encapsuladoras devem exercer um papel importante nessa complexidade e, assim, auxiliam no propósito argumentativo.

Em textos argumentativos, o planejamento pode contribuir para a defesa de um ponto de vista. Coroa (2017, p. 52) sugere que a escrita desse tipo de texto segue um mapeamento por parte do autor: "a cada marca ou pista, ele avança, recua ou reorienta seu caminho." No caso dos textos nota 1000, considerando a avaliação criteriosa, o planejamento se materializa na completa coerência do texto com relação: i) ao ponto de vista defendido; ii) aos argumentos que o sustentam; e iii) às propostas de intervenção sugeridas pelo candidato.

$\mathrm{Na}$ redação do Enem, exige-se que a argumentação seja apoiada por uma exposição variada do tema: é aqui que o repertório vai contribuir para a dissertação. Coroa (2017) e Cantarin, Bertucci e Almeida (2017) mostram que a dissertação, entendida como exposição ou aprofundamento do tema, é essencial no texto do Enem. Nesse sentido, a redação também requer uma descrição de diferentes aspectos e relativamente aprofundada do tema, de tal forma que os argumentos se sustentem nesse contexto. O uso recorrente de verbos estativos (ser e estar, por exemplo) e de adjetivos deve indicar que o texto está dissertando sobre o tema e, ao mesmo tempo, argumentando, pela escolha de tais itens, conforme sugerem Cantarin et al. (2017, p. 83). Nesse sentido, podemos sugerir igualmente que é plenamente possível se encontrar encapsulamentos com teor descritivo, os quais contribuem para a progressão da dissertação, ou seja, para o aprofundamento do tema.

Tudo isso vai ao encontro do que se lê na cartilha do participante do Enem (Brasil, 2017), a qual detalha que o candidato precisa defender um ponto de vista com argumentos consistentes e elencar uma proposta de intervenção para o problema discutido. Nesse sentido, os textos analisados aqui cumpriram de modo exemplar essas indicações, já que foram avaliados com a nota máxima pela banca de correção.

A mesma cartilha detalha aos candidatos as cinco competências avaliadas no processo, indicando inclusive uma matriz de referência de notas, em que se apontam os motivos pelos quais os avaliadores atribuem notas de 0 a 200 para cada competência. O Quadro 1 resume os objetivos de cada competência e apresenta a descrição do modo como se avalia um texto com nota máxima em cada uma delas. 
Competencia Objetivo Para nota máxima (200 pontos)

1 Demonstrar domínio da modalidade escrita formal da língua portuguesa.

2

Compreender a proposta de redação e aplicar conceitos das várias áreas de conhecimento para desenvolver o tema, dentro dos limites estruturais do texto dissertativo-argumentativo em prosa.

3

Selecionar, relacionar, organizar e interpretar informações, fatos, opiniões e argumentos em defesa de um ponto de vista.

4

Demonstrar conhecimento dos mecanismos linguísticos necessários para a construção da argumentação.

5

Elaborar proposta de intervenção para o problema abordado, respeitando os direitos humanos.
Demonstra excelente domínio da modalidade escrita formal da língua portuguesa e de escolha de registro. Desvios gramaticais ou de convenções da escrita serão aceitos somente como excepcionalidade e quando não caracterizarem reincidência.

Desenvolve o tema por meio de argumentação consistente, a partir de um repertório sociocultural produtivo, e apresenta excelente domínio do texto dissertativoargumentativo.

Apresenta informações, fatos e opiniões relacionados ao tema proposto, de forma consistente e organizada, configurando autoria, em defesa de um ponto de vista.

Articula bem as partes do texto e apresenta repertório diversificado de recursos coesivos

Elabora muito bem proposta de intervenção, detalhada, relacionada ao tema e articulada à discussão desenvolvida no texto.

Fonte: Brasil (2017).

Quadro 1 - Competências avaliadas na redação do Enem.

Nesse sentido, podemos dizer que a coesão textual tem um papel preponderante na articulação das competências. Em especial, quando se analisa a importância da Competência 4, percebe-se que ela é central para a tessitura do texto, na medida em que valoriza o emprego de elementos linguísticos essenciais para sua composição. Isso pode ser percebido em diferentes textos publicados na coletânea de subsídios para avaliação de textos do Enem (Garcez; Corrêa, 2017). Val e Mendonça (2017, p. 205), por exemplo, afirmam que

os recursos coesivos facilitam ao leitor compreender o texto como um todo que faz sentido e apreender sua orientação argumentativa. Isso significa que a coesão é um trabalho linguístico construído entre os interlocutores do discurso. De um lado, o locutor seleciona recursos que, contribuindo para a tessitura do texto, ajudam a manifestar seu ponto de vista, os efeitos de sentido que intenciona suscitar. De outro lado, o interlocutor, para produzir sua compreensão, leva em conta a materialidade linguística do texto, promovendo a articulação entre elementos tomados como inter-relacionáveis. 
Com isso, a coesão tem um papel decisivo na avaliação do texto: é pela materialidade linguística que o avaliador compreenderá o caminho argumentativo escolhido pelo autor; e é esse caminho que será avaliado quantitativamente com uma nota específica - no caso desta pesquisa, sempre a nota 1000 .

Para essa efetivação, diferentes autores da coletânea ressaltam o papel das anáforas em textos estilo Enem (Elias, 2017; Val; Mendonça, 2017; Aquino, 2017). No entanto, apenas Elias (2017, p. 131) menciona o caso dos encapsulamentos:

\begin{abstract}
Ainda em se tratando de remissão textual, fato bastante comum é o uso de uma forma nominal para resumir porções textuais e transformar essa porção em um referente. O referente que resulta desse encapsulamento é denominado de rótulo, defende Francis (2003). O rótulo é um importante sinalizador da orientação argumentativa que o produtor imprime ao texto (...). (Elias, 2017, p. 131, grifo do autor)
\end{abstract}

Após essa apresentação geral sobre os encapsulamentos, Elias (2017) os discute em um texto argumentativo, mas não do modelo de redação do Enem, tal como pretendemos verificar neste trabalho.

Reconhecendo essa lacuna na discussão sobre as anáforas encapsuladoras, em especial no ensino, assumimos a importância desse fenômeno coesivo na composição de textos argumentativos escritos, tal como afirma Conte (2003). Ao lançarmos luz sobre a questão, esperamos que isso ajude a melhorar o entendimento dos processos de leitura e de produção textual.

Por fim, ressaltamos que o conjunto em análise na presente pesquisa é composto de textos que cumpriram com excelência todos os requisitos indicados pelas competências. Sendo exemplares prototípicos levantamos a hipótese de que os encapsulamentos podem se caracterizar por itens recorrentes, os quais podem estar intimamente ligados às características do gênero textual em questão. ${ }^{8}$ Mais especificamente, as anáforas encapsuladoras aparecem na Competência 4, que trata dos elementos coesivos. Partindo do princípio de que os textos em análise são modelos, a presença de encapsulamentos pode indicar uma estratégia importante na articulação das partes do texto. Finalmente, essa articulação contribui decisivamente para a organização do texto, tecendo-o de forma competente e consistente em defesa de um ponto de vista, exigência da Competência 3. Feitos esses apontamentos, passamos à análise dos dados.

\title{
4 ANÁFORAS ENCAPSULADORAS EM REDAÇÕES NOTA 1000
}

\subsection{Metodologia}

Para esta pesquisa, tomamos como corpus de análise um conjunto de textos de redação nota 1000 do Enem: a Cartilha Redação a Mil: 30 redações do Enem $2018^{9}$. Ela foi criada pelos próprios autores das redações e compilada por Lucas Felpi, um dos candidatos com nota máxima, e contempla trinta e uma das cinquenta e cinco que obtiveram nota máxima na área de conhecimento Redação, no Exame Nacional do

\footnotetext{
${ }^{8}$ Sobre prototipicidade do gênero redação do Enem, recomendamos Pereira (2018) e Bertucci (2018).

${ }^{9}$ Disponível em: < https://vestibular.brasilescola.uol.com.br/arquivos/cartilha-redacao-a-mil2018.pdf>. Acesso em: 05 mai. 2019.
} 
Ensino Médio. Os autores são jovens, em sua maioria do gênero feminino, oriundos de todas as regiões do Brasil. O projeto, disponível gratuitamente na rede, pretende servir de inspiração e contribuição para o desenvolvimento e o aperfeiçoamento da produção textual de outros candidatos, sendo que, para os mais de seis milhões de inscritos no Enem daquele ano, "um mau resultado na escrita pode[ria] custar a tão sonhada vaga na universidade." (Salvador, 2013, p. 7).

Dada a natureza da proposta de produção de escrita do Enem, texto dissertativo-argumentativo, o candidato é avaliado por intermédio de competências (Quadro 1), dentre as quais destacamos as seguintes:

3. Selecionar, relacionar, organizar e interpretar informações, fatos, opiniões e argumentos em defesa de um ponto de vista.

4. Demonstrar conhecimento dos mecanismos linguísticos necessários para a construção da argumentação.

As duas competências supracitadas revelam diretamente a importância das anáforas encapsuladoras nessa proposta, pois os quesitos descritos nela são os fundamentos do encapsulamento, cujo objetivo é, além de organizar e dar fluidez ao texto, guiar o leitor para o caminho traçado pelo autor.

Pela quantidade de textos (31 redações e quase 14 mil palavras), decidimos seguir os passos indicados no Quadro 2 para a preparação e posterior análise do corpus.

\begin{tabular}{|c|c|c|}
\hline Passo & Ação & Objetivo \\
\hline 1. Preparação do arquivo & $\begin{array}{c}\text { Seleção da versão em texto das } \\
\text { redações }\end{array}$ & $\begin{array}{c}\text { Facilitar a localização das } \\
\text { anáforas. }\end{array}$ \\
\hline 2. Busca e realce de expressões & $\begin{array}{c}\text { No arquivo de texto, localizamos } \\
\text { as expressões encabeçadas pelos } \\
\text { demonstrativos esse, essa, desse, } \\
\text { dessa e tal }\end{array}$ & $\begin{array}{c}\text { Identificar as ocorrências para } \\
\text { serem quantificadas e qualificadas } \\
\text { no trabalho. }\end{array}$ \\
\hline 3. Análise individual & $\begin{array}{l}\text { Análise qualitativa de cada } \\
\text { ocorrência }\end{array}$ & $\begin{array}{l}\text { Classificar a ocorrência a partir } \\
\text { das características apontadas. }\end{array}$ \\
\hline
\end{tabular}

Fonte: Elaboração própria.

Quadro 2 - Etapas da metodologia.

Feita a preparação do corpus, a terceira etapa foi a análise individual dos textos. Nesse caso, estipulamos alguns critérios para a classificação das anáforas.

(i) Consideramos apenas as anáforas encapsuladoras cujos sintagmas eram introduzidos por essa, esse, dessa, desse e tal. ${ }^{10}$

(ii) Excluímos casos em que essas expressões formavam conectivos, como desse modo ou dessa forma, por entendermos se tratar de um caso

\footnotetext{
10 A literatura ressalta o papel dos demonstrativos no fenômeno. Conte (2003, p. 178), inclusive, afirma que os encapsulamentos anafóricos revelam "uma clara preferência por um determinante demonstrativo". Por isso, o recorte desta pesquisa está nos sintagmas com demonstrativos.
} 
complexo, que pode ter relação com a anáfora, mas sem contemplação na literatura consultada.

(iii) Excluímos tanto os casos com o pronome isso, por sua complexidade, quanto aqueles com anáfora fiel, por não serem encapsulamentos.

Conforme apontamos na seção teórica, os encapsulamentos têm uma função básica de construírem objetos-de-discurso e, consequentemente, contribuírem para a progressão textual. Por outro lado, podem indicar rótulos avaliativos, expressando a opinião do produtor. Por isso, os casos de anáfora encapsuladora foram classificados conforme o Quadro 3, a seguir.

\begin{tabular}{|l|l|l|}
\hline \multicolumn{2}{|c|}{ Anáfora encapsuladora } & \multicolumn{1}{c|}{ Explicação } \\
\hline 1. Descritiva & AED & $\begin{array}{l}\text { Expressão genérica para referenciar um trecho do } \\
\text { discurso }\end{array}$ \\
\hline 2. Opinativa & AEO & $\begin{array}{l}\text { Expressão subjetiva para emitir opinião sobre um trecho } \\
\text { do discurso }\end{array}$ \\
\hline
\end{tabular}

Fonte: Elaboração prória.

Quadro 3 - Classificação dos encapsulamentos aplicados aos dados.

As interpretações analíticas, em que analisamos o papel de cada encapsulamento no conjunto argumentativo em que aparece, serão realizadas depois da apresentação da quantificação. Aliás, por razões de espaço, vamos analisar duas redações apenas: uma com predominância de AED e outra com mais casos de AEO. Com isso, objetivamos ilustrar como elas atuam na composição textual, a fim de melhor compreender as estratégias de argumentação presentes ali.

\subsection{Resultados e discussão}

Primeiramente, vamos apresentar os dados gerais de cada texto nas Tabelas 1 e 2 .

Tabela 1 - Dados gerais dos encapsulamentos - Textos 1 a 16.

\begin{tabular}{lllllllllllllllll} 
Texto & 1 & 2 & 3 & 4 & 5 & 6 & 7 & 8 & 9 & 10 & 11 & 12 & 13 & 14 & 15 & 16 \\
\hline AED & 8 & 1 & 3 & 5 & 1 & 0 & 2 & 2 & 2 & 6 & 2 & 0 & 3 & 2 & 2 & 3 \\
AEO & 0 & 3 & 4 & 2 & 0 & 0 & 0 & 1 & 0 & 0 & 0 & 0 & 1 & 0 & 0 & 0 \\
\hline Total & 8 & 4 & 7 & 7 & 1 & 0 & 2 & 3 & 2 & 6 & 2 & 0 & 4 & 2 & 2 & 3
\end{tabular}

Fonte: Elaboração própria, com dados da Cartilha redação a mil.

Tabela 2 - Dados gerais dos encapsulamentos - Textos 17 a 31.

\begin{tabular}{cccccccccccccccc} 
Texto & $\mathbf{1 7}$ & $\mathbf{1 8}$ & $\mathbf{1 9}$ & $\mathbf{2 0}$ & $\mathbf{2 1}$ & $\mathbf{2 2}$ & $\mathbf{2 3}$ & $\mathbf{2 4}$ & $\mathbf{2 5}$ & $\mathbf{2 6}$ & $\mathbf{2 7}$ & $\mathbf{2 8}$ & $\mathbf{2 9}$ & $\mathbf{3 0}$ & $\mathbf{3 1}$ \\
\hline AED & 4 & 1 & 5 & 5 & 2 & 2 & 1 & 6 & 5 & 4 & 5 & 2 & 3 & 5 & 1 \\
AEO & 2 & 0 & 0 & 3 & 0 & 1 & 0 & 1 & 0 & 0 & 3 & 1 & 0 & 1 & 0 \\
\hline Total & 6 & 1 & 5 & 8 & 2 & 3 & 1 & 7 & 5 & 4 & 8 & 3 & 3 & 6 & 1
\end{tabular}

Fonte: Elaboração própria, com dados da Cartilha redação a mil. 
Se somarmos os casos apresentados e estipularmos um percentual, veremos que as ocorrências de AED são bem mais frequentes que as de AEO: 90 (79\%) e 24 (21\%), respectivamente. Além disso, apenas duas redações nota 1000 (6 e 12) não apresentam anáforas encapsuladoras como as que recortamos para esta pesquisa. Nesse ponto, podemos entender que o uso predominante de encapsulamentos descritivos tem relação direta com a noção mais genérica e de indefinitude que eles apresentam. No geral, observaram-se muitas ocorrências de anáforas com nomes como prática, questão, realidade e processo (3 ocorrências de cada), os quais não apresentaram, no todo discursivo do texto, um caráter avaliativo. Ainda que a subjetividade tenha interferido na escolha lexical, como vimos ser o caso dos encapsulamentos, a utilização de expressões com direcionamento argumentativo mais forte foi menos frequente.

Acrescente-se também o fato de somente duas redações apresentarem a predominância das AEO sobre as AED (Redações 2 e 3), enquanto nas demais 27, a predominância é das AED. Isso é uma pista de que o encapsulamento é uma estratégia diversificada, não sendo, em si, opinativo por excelência, ainda que contribua para a orientação argumentativa do texto.

Tais números apontam para um aspecto importante: primordialmente, os encapsulamentos contribuem para a construção de objetos de discurso referenciados e para a tessitura textual, sem que se pressuponha uma necessária opinião do autor do texto. Apesar disso, não desprezamos a subjetividade que, certamente, está presente em todas as escolhas, seja nas AED, seja nas AEO.

Para visualizar essa subjetividade, precisamos de uma análise qualitativa e, como indicamos antes, vamos tomar dois exemplos de análise: uma com predominância de AED (Redação 1, com 8 casos de AED e zero de AEO) e outra com mais casos de AEO (Redação 3, com 5 de AEO casos e 2 de AED). Comecemos pela primeira.

Segundo Steve Jobs, um dos fundadores da empresa "Apple", a tecnologia move o mundo. Contudo, os avanços tecnológicos não trouxeram apenas avanços à sociedade, uma vez que bilhões de pessoas sofrem a manipulação oriunda do acesso aos seus dados no uso da internet. Nesse sentido, esse processo é executado por empresas que buscam potencializar a notoriedade dos seus produtos e conteúdos no meio virtual. Sob tal ótica, esse cenário desrespeita princípios importantes da vida social, a saber, a liberdade e a privacidade.

De acordo com Jean Paul Sartre, o homem é condenado a ser livre. Nessa lógica, o uso de informações do acesso pessoal para influenciar o usuário confronta o pensamento de Sartre, visto que o indivíduo tem sua liberdade de escolha impedida pela imposição de conteúdos a serem acessados. Dessa forma, a internet passa a ser um ambiente pouco democrático e torna-se um reflexo da sociedade contemporânea, na qual as relações de lucro e interesse predominam. Faz-se imprescindível, portanto, a dissolução dessa conjuntura.

Outrossim, é válido ressaltar que, conforme Immanuel Kant, o princípio da ética é agir de forma que essa ação possa ser uma prática universal. De maneira análoga, a violação da privacidade pelo acesso aos dados virtuais sem a permissão das pessoas vai de encontro à ética kantiana, dado que se todos os cidadãos desrespeitassem a privacidade alheia, a sociedade entraria em profundo desequilíbrio. Com base nisso, o uso de informações virtuais é prejudicial à ordem social e, por conseguinte, torna-se contestável quando executado sem consentimento. 
Em suma, são necessárias medidas que atenuem a manipulação do comportamento do usuário pelo controle de dados na internet. Logo, a fim de dar liberdade de escolha ao indivíduo, cabe às empresas de tecnologia solicitar a autorização para o uso dessas informações, por meio de advertências com linguagem clara, tendo em vista a linguagem técnica utilizada, atualmente, por avisos do tipo. Ademais, compete ao cidadão ficar atento a essa questão, de modo a cobrar e pressionar essas empresas. Enfim, a partir dessas ações, as tecnologias, como disse Steve Jobs, moverão o mundo para frente. (Redação 1, Cartilha redação a mil, 2019, p. 4-5, grifo nosso)

Antes da análise, devemos lembrar que casos como nesse sentido (1 ${ }^{\circ}$. parágrafo), foram excluídos por causa do Critério (i), indicado na metodologia; outros como dessa forma ( $2^{\circ}$. parágrafo) foram excluídos conforme o Critério (ii); e, finalmente, outros como nisso ( $3^{\circ}$. parágrafo) não foram considerados para a análise por causa dos Critérios (i) e (iii). Também as vezes em que houve a presença de anáfora fiel, elas não foram computadas. É o caso de essas empresas ( $4^{\circ}$. parágrafo), que não foi considerado como encapsulamento porque empresas aparece na terceira linha desse mesmo parágrafo.

Focando os casos de anáfora encapsuladora nessa redação, percebemos que os oito casos destacados são casos de sumarização geral, com uso de uma expressão mais genérica e menos opinativa para o processo de rotulagem. São, portanto, casos de AED. Ainda que diferentes leitores possam preencher a referência discursiva de forma diversa, sugerimos que há alguns direcionamentos possíveis. É o caso, por exemplo, de "esse processo", no primeiro parágrafo, que retoma e rotula como processo o trecho "manipulação oriunda do acesso aos seus [de bilhões de pessoas] dados no uso da internet". No mesmo parágrafo, é relevante o caso de duas AED que ocorrem no mesmo período: "tal ótica", que caracteriza uma perspectiva de marketing do uso de dados por parte das empresas; e "esse cenário", que retoma todo o trecho anteriormente citado, a partir de "Contudo, os avanços....". Esse processo de encapsulamento no texto revela uma boa coesão, capaz de mostrar o direcionamento argumentativo do autor do texto, ainda que sem usar AEOs.

Destaca-se ainda, como dito na análise geral, o caráter genérico dos núcleos desses sintagmas encapsuladores. Em todos eles, o substantivo tem referência abstrata, o que favorece a indeterminação e a possibilidade de encapsular. Outro ponto importante é a relação de inferência que se pode estabelecer entre as AEDs e os possíveis trechos a que se referem. Como exemplo, podemos citar "informações", que se relaciona com "dados". Ali, o conjunto de itens que os dados carregam podem ser todos rotulados como "informações" - que nos parece um termo mais genérico que "dados".

Agora, passamos à Redação 3, com predominância de AEO.

\footnotetext{
"Black Mirror" é uma série americana que retrata a influência da tecnologia no cotidiano de uma sociedade futura. Em um de seus episódios, é apresentado um dispositivo que atua como uma babá eletrônica mais desenvolvida, capaz de selecionar as imagens e os sons que os indivíduos poderiam vivenciar. Não distante da ficção, nos dias atuais, existem algoritmos especializados em filtrar informações de acordo com a atividade "online" do cidadão. Por isso, torna-se necessário o debate acerca da manipulação do comportamento do usuário pelo controle de dados na internet.
}

Primeiramente, é notável que o acesso a esse meio de comunicação ocorre de maneira, cada vez mais, precoce. Segundo pesquisa divulgada pelo IBGE, no ano de 2016, apenas 35\% dos entrevistados, que apresentavam idade igual ou superior a 10 anos, nunca haviam 
utilizado a internet. Isso acontece porque, desde cedo, a criança tem contato com aparelhos tecnológicos que necessitam da disponibilidade de uma rede de navegação, que memoriza cada passo que esse jovem indivíduo dá para traçar um perfil de interesse dele e, assim, fornecer assuntos e produtos que tendem a agradar ao usuário. Dessa forma, o uso da internet torna-se uma imposição viciosa para relações sócio-econômicas.

Em segundo lugar, o ser humano perde a sua capacidade de escolha. Conforme o conceito de "Mortificação do Eu", do sociólogo Erving Goffman, é possível entender o que ocorre na internet que induz o indivíduo a ter um comportamento alienado. Tal preceito afirma que, por influência de fatores coercitivos, o cidadão perde seu pensamento individual e junta-se a uma massa coletiva. Dentro do contexto da internet, o usuário, sem perceber, é induzido a entrar em determinados sites devido a um "bombardeio" de propagandas que aparece em seu dispositivo conectado. Evidencia-se, portanto, uma falsa liberdade de escolha quanto ao que fazer no mundo virtual.

Com o intuito de amenizar essa problemática, o Congresso Nacional deve formular leis que limitem esse assédio comercial realizado por empresas privadas, por meio de direitos e punições aos que descumprirem, a fim de acabar com essa imposição midiática. As escolas, em parceria com as famílias, devem inserir a discussão sobre esse tema tanto no ambiente doméstico quanto no estudantil, por intermédio de palestras, com a participação de psicólogos e especialistas, que debatam acerca de como agir "online", com o objetivo de desenvolver, desde a infância, a capacidade de utilizar a tecnologia a seu favor. Feito isso, o conflito vivenciado na série não se tornará realidade. (Redação 3, Cartilha redação a mil, 2019, p. 10-11, grifo nosso).

Não precisamos comentar os casos de exclusão, por isso, focaremos diretamente nos casos de anáfora encapsuladora. Aqui, identificamos 7 ocorrências dentro dos critérios que estabelecemos. Os casos de AED estão no segundo parágrafo ( 2 ocorrências) e no último ("esse tema"). Assim como se viu na primeira redação sob análise, os encapsulamentos aqui estão bem ajustados à necessidade de coesão textual, de modo que garantem uma progressão e uma sequenciação adequada do texto em seu direcionamento argumentativo.

Nosso interesse, no entanto, reside nas quatro ocorrências de AEO. Primeiramente, reforçamos que os encapsulamentos são construídos no discurso e não têm uma relação extensional com o mundo. Por isso, cabe o leitor tentar recuperar sua referência, em geral feita de forma genérica. Além disso, ele possui um caráter de avaliação (de rótulo). Juntando tais características, no terceiro parágrafo, entendemos que "tal preceito" recupera a ideia de Erving Goffman, mas, ao mesmo tempo, classifica a posição do autor como uma regra. Com isso, o candidato estabelece um vínculo importante entre a posição de Goffman e a explicação que dará na sequência, diretamente relacionada à discussão sobre a liberdade e a individualidade do sujeito. Por isso, indicamos esse caso como AEO. O avaliador, ao se deparar com esse elemento linguístico, observa não só o emprego anafórico, como também o direcionamento argumentativo pretendido pelo autor. É, pois, um sinal de habilidade de escrita, que preenche os requisitos de um texto adequado ao gênero solicitado, em especial pelas Competências 3 e 4, conforme já observamos na análise geral. Ainda que outra leitura possível para "preceito" fosse uma lição (e não regra), isso ratificaria a noção genérica das anáforas encapsuladoras e continuaria levando o leitor (avaliador) a perceber que o candidato considera a posição de Erving Goffman algo a ser ensinado ou mesmo seguido (o que é próprio de uma lição).

Menos polêmicos, porém, são os exemplos no último parágrafo. Em “essa problemática" temos um caso evidente de AEO, porque o autor recupera toda a 
discussão sobre a manipulação via internet, tema do texto, e a rotula como problema. Ora, classificar uma determinada situação como problemática é indicar um posicionamento argumentativo importante, já que, para isso, espera-se que tenham sido indicados argumentos ${ }^{11}$. No caso do texto, isso não só aconteceu, como também houve a proposta de intervenção (apresentada no último parágrafo) alinhada com o desafio da problemática apresentada. Tudo isso foi avaliado como totalmente adequado pela banca avaliadora, que concedeu 1000 ao texto.

A expressão "esse assédio comercial", recupera a ação das empresas sobre os usuários da internet, dissertada ao longo do texto. Assim como o caso anterior, é um ótimo exemplo do papel sumarizador dos encapsulamentos que recuperam porções de textos de tamanho variado para construir um objeto discursivo referenciado. Mais especificamente sobre o papel da AEO, essa anáfora direciona o leitor para entender a posição do autor, contrário ao papel das empresas sobre os usuários, o que, fatalmente, o levará a pedir providências sobre elas, como indica antes pela exigência de leis.

De modo semelhante, a expressão "essa imposição midiática", que recupera o caso do excesso de propagandas divulgadas pelas empresas via internet, é extremamente opinativa. Aqui, "imposição" sugere algo feito sem a anuência do usuário (ou pelo menos seu claro conhecimento), sendo uma forma de classificar a ação das empresas como ilegal. Nesse sentido, a anáfora promove o fortalecimento da tese do candidato, contribuindo para o caminho argumentativo que vem construindo, tal como temos defendido ser o papel das AEO nesses textos ${ }^{12}$.

Finalmente, elencamos no Quadro 4, em ordem de maior para a menor frequência, as ocorrências com repetição que aparecem nos 31 textos, com a classificação que consideramos pertinente em cada caso. Destaca-se, nesses casos, o maior uso de "essa problemática" e "esse cenário" (ambos com 4 casos). Outro ponto importante é que, nas repetições, houve apenas um caso de anáfora opinativa, com o núcleo "problemática": os 4 já citados e mais 2 encabeçados por "tal". Outro ponto importante com relação aos núcleos é que "quadro" apareceu também 4 vezes, com "desse" e "tal" encabeçando a anáfora.

Como se vê no final do quadro, são 42 casos de repetição. Considerando o total de 114 casos de encapsulamentos nesses textos, há 37\% de anáforas repetidas. Tal fato sinaliza para uma recorrência de elementos linguísticos nesses textos, o que é algo que vem sendo observado em outros trabalhos. Analisando corpora de 16 redações nota 1000, Pereira (2018) e Bertucci (2018), em trabalhos distintos, verificaram um alto índice de verbos factivos, em detrimento de outros tipos (estativos e declarativos, por exemplo), bem como alta modalização de intensidade e modo, além da ausência completa de marcadores de primeira ou segunda pessoa.

\footnotetext{
11 Vale comentar que problema (e variações) é uma ocorrência comum nos casos de encapsulamentos no corpus em análise.

12 A proposta de análise desses casos não esgota outros possíveis significados que os AEOs tenham no texto. No entanto, procuramos ilustrar que, independentemente do caso, são extremamente adequados às condições de produção exigidas no gênero.
} 


\begin{tabular}{lll} 
Encapsulamento & Classificação & Número de ocorrências \\
\hline Essa problemática & AEO & 04 \\
Esse cenário & AED & 04 \\
Essa prática & AED & 03 \\
Essa questão & AED & 03 \\
Essa realidade & AED & 03 \\
Esse processo & AED & 03 \\
Esse viés & AED & 03 \\
Tal ação & AED & 03 \\
Dessa ideia & AED & 02 \\
Desse quadro & AED & 02 \\
Essa ótica & AED & 02 \\
Essa perspectiva & AED & 02 \\
Esse panorama & AED & 02 \\
Tal ótica & AED & 02 \\
Tal problemática & AEO & 02 \\
Tal quadro & AED & 02 \\
\hline & TOTAL & 42 \\
& &
\end{tabular}

Fonte: Elaboração própria.

Quadro 4 - Lista dos encapsulamentos com mais de uma ocorrência.

Ressalta-se aqui que a ocorrência dos encapsulamentos recortados para essa pesquisa é alta nos textos, com média de quase quatro casos por redação $(3,67)$. Isso reforça a importância desse mecanismo para a construção de textos do gênero sob análise. O mecanismo de encapsular, como uma ação de referenciação sobre o discurso que se apresenta no texto, contribui para a dissertação e a argumentação, já que é um modo de organizar e interpretar elementos ali presentes. Tal fato vai ao encontro das exigências para uma boa produção textual, como se discutiu na seção sobre redação e, em especial, preenche os requisitos exigidos nas Competências 3 e 4 do Enem.

Assim, as análises aqui apresentadas vão também ao encontro das conclusões dos trabalhos de Bertucci (2006) e Cordeiro (2006), que ressaltam a importância do uso das anáforas encapsuladoras em produções do tipo argumentativo, uma vez que elas promovem uma melhor articulação do texto por meio de rotulações, de modo a estabelecer a progressão e a manutenção temática entre os blocos. Ademais, esses rótulos podem conduzir o leitor ao entendimento adequado desejado pelo autor, ou seja, contribuem na estratégia de convencimento.

\section{CoNClusão}

Neste artigo, pudemos estudar diferentes ocorrências de anáforas encapsuladoras em redações do Enem, avaliadas com a nota máxima no exame de 2018. Com o objetivo de explicar a função desses elementos no texto, concluímos, 
primeiro, que, das 31 redações analisadas, apenas duas delas não apresentaram nenhum caso de encapsulamento dentro dos critérios estabelecidos por nós. Além disso, também verificamos que há uma ocorrência maior das anáforas mais descritivas $(79 \%)$, em comparação com as opinativas (21\%).

Do ponto de vista qualitativo, identificamos os casos de anáforas encapsuladoras como essenciais para a manutenção da coesão textual, já que resumem uma parte textual precedente e, ao mesmo tempo, constroem um objeto discursivo referenciado. Além desse papel coesivo, elas podem ser importantes modos de marcação da opinião do candidato com relação ao tema apresentado, oferecendo ao leitor uma visão clara daquilo que pensa e defende o autor. Tais conclusões vão ao encontro do que a literatura discutida no texto apregoa, confirmando a relevância do tema.

Assim, os encapsulamentos podem ser tomados como recategorizações importantes na tessitura coesiva e na articulação do ponto de vista, o que os Critérios 3 e 4 exigem como fatores essenciais no texto do Enem, conforme observamos aqui. Nesse sentido, o presente trabalho também se insere no conjunto de análise sobre as características deste gênero textual de suma importância no contexto nacional, já que, há anos, mais de 4 milhões de candidatos realizam a redação do Enem (em 2018, foram 4,1 milhões de redações). Com esse número, ela deve ser um dos gêneros mais produzidos por ano no país, porque ao número de provas ainda se somam as redações produzidas ao longo da vida escolar como preparação para o Exame.

O leitor deve ter notado que algumas questões ficaram em aberto, como o caso da posição dos encapsulamentos. Eles apresentam variação nos exemplos discutidos aqui: o texto 2 , por exemplo, tem 4 dos 7 casos, em meio de período. No entanto, por razões de espaço, deixamos em aberto, para futuros trabalhos, a posição de ocorrência dos encapsulamentos, algo importante a se verificar do ponto de vista da relação entre sintaxe e argumentação. Em outras palavras, poderíamos perguntar: em que posição esses elementos mais ocorrem? Essa posição favorece a argumentação apresentada?

Outro ponto que nos parece igualmente relevante, mas que ficou de fora da análise é a possibilidade de relacionar as AEOs com as implicaturas. Conte (2003) já aponta para uma relação entre os encapsulamentos e a pragmática, em especial com relação aos casos de metadiscursividade (que também não analisamos nesta pesquisa). No entanto, o que nos parece é que os AEOs carregam uma implicatura convencional, tal como ocorrem em casos com (in)felizmente em (In)felizmente, Maria vai à festa. Nesse caso, há uma informação (Maria vai à festa) e uma avaliação do produtor da sentença sobre isso (ele está feliz ou triste com isso). Trabalhos como de Oliveira e Basso (2014) e Tauil (2017) poderiam lançar luz para esse interessante fenômeno.

Com isso, esperamos ter ressaltado ainda mais o papel das anáforas encapsuladoras em textos de opinião, tal como se viu em outros estudos. E, seguindo Cordeiro (2006), esperamos também inspirar trabalhos com esses elementos em sala, já que podem ajudar o aluno a desenvolver uma competência de escrita cada vez melhor, em especial para a argumentação.

\section{REFERÊNCIAS}

Apothéloz D. Papel e funcionamento da anáfora na dinâmica textual. In: Cavalcante MM, Rodrigues BB, Ciulla A, organizadores. Referenciação. São Paulo: Contexto; 2003. p. 53-84. 
Aquino MFS. A coesão na tessitura textual: avaliação do emprego de recursos coesivos. In: Garcez LHC, Corrêa VR, organizadores. Textos dissertativo-argumentativos: subsídios para a qualificação de avaliadores. Brasília: Instituto Nacional de Estudos e Pesquisas Educacionais Anísio Teixeira; 2017. p. 213-220.

Bertucci RA. Anáforas encapsuladoras: uma análise em textos de opinião. Revista Letras, 2006;70:207221. [citado 10 fev. 2019]. Disponível em: https://revistas.ufpr.br/letras/article/view/5429

Bertucci RA. Recurso computacional para análise de textos argumentativos [internet]. Curitiba: Universidade Tecnológica Federal do Paraná. [citado em 15 nov. 2018]. Disponível em: http://paginapessoal.utfpr.edu.br/bertucci/publicacoes-trabalhos-academicos/apresentacoes

Brasil. Redação no Enem 2017: cartilha do participante. Brasília: Diretoria de Avaliação da Educação Básica/ Instituto Nacional de Estudos e Pesquisas Educacionais Anísio Teixeira/ Ministério da Educação; 2017. [citado 19 jul. 2019]. Disponível em:

http://download.inep.gov.br/educacao_basica/enem/guia_participante/2017/manual_de_redacao_d o_enem_2017.pdf

Cançado M et al.. Subjetividade em correções de redações: detecção automática através de léxico de operadores de viés linguístico. Linguamática [Internet], 2020; 12(1):63-79. [citado 25 de Agosto de 2020]. Disponível em: https://www.linguamatica.com/index.php/linguamatica/article/view/313

Cantarin M, Bertucci RA, Almeida RC. A análise do texto dissertativo-argumentativo. In: Garcez LHC, Corrêa VR, organizadores. Textos dissertativo-argumentativos: subsídios para a qualificação de avaliadores. Brasília: Instituto Nacional de Estudos e Pesquisas Educacionais Anísio Teixeira; 2017. p. 81-91.

Cavalcante MM. Apresentação. In: Cavalcante MM, Rodrigues BB, Ciulla A, organizadores.

Referenciação. São Paulo: Contexto; 2003a. p. 09-16.

Cavalcante MM. Expressões referenciais - uma proposta classificatória. Caderno de Estudos Linguísticos, 2003b;44:105-18. [citado 14 nov. 2019]. Disponível em:

https://periodicos.sbu.unicamp.br/ojs/index.php/cel/article/view/8637068

Cavalcante MM. Anáfora e dêixis: quando as retas se encontram. In: Koch IGV, Morato EM, Bentes AC, organizadores. Referenciação e discurso. São Paulo: Contexto; 2005. p. 125-149.

Conte ME. Encapsulamento anafórico. In: Cavalcante MM, Rodrigues BB, Ciulla A, organizadores. Referenciação. São Paulo: Contexto; 2003. p. 177-190.

Coroa ML. O texto dissertativo-argumentativo. In: Garcez LHC, Corrêa VR, organizadores. Textos dissertativo-argumentativos: subsídios para a qualificação de avaliadores. Brasília: Instituto Nacional de Estudos e Pesquisas Educacionais Anísio Teixeira; 2017. p. 59-71.

Cordeiro MAS. A contribuição da anáfora encapsuladora para a organização da informação em dissertações produzidas por alunos do $3^{\circ}$ ano do ensino médio de Santarém [dissertação]. Belém: Instituto de Letras e Comunicação, Universidade Federal do Pará; 2006. [citado 25 ago. 2020]. Disponível em: http://repositorio.ufpa.br:8080/jspui/handle/2011/9421

Elias VMS. Texto e argumentação. In: Garcez LHC, Corrêa VR, organizadores. Textos dissertativoargumentativos: subsídios para a qualificação de avaliadores. Brasília: Instituto Nacional de Estudos e Pesquisas Educacionais Anísio Teixeira; 2017. p. 117-136.

Francis G. Rotulação do discurso: um aspecto da coesão lexical de grupos nominais. In: Cavalcante MM, Rodrigues BB, Ciulla A, organizadores. Referenciação. São Paulo: Contexto; 2003. p. 191-228. 
Garcez LHC. Gênero e tipo de texto. In: Garcez LHC, Corrêa VR, organizadores. Textos dissertativoargumentativos: subsídios para a qualificação de avaliadores. Brasília: Instituto Nacional de Estudos e Pesquisas Educacionais Anísio Teixeira; 2017a. p. 51-58.

Garcez LHC. O ensino de redação. In: Garcez LHC, Corrêa VR, organizadores. Textos dissertativoargumentativos: subsídios para a qualificação de avaliadores. Brasília: Instituto Nacional de Estudos e Pesquisas Educacionais Anísio Teixeira; 2017b. p. 275-278.

Garcez LHC, Corrêa VR. Textos dissertativo-argumentativos: subsídios para a qualificação de avaliadores. Brasília: Instituto Nacional de Estudos e Pesquisas Educacionais Anísio Teixeira; 2017. [citado em 13 mar. 2020] Disponível em: http://portal.inep.gov.br/documents/186968/484421/TEXTOS+DISSERTATIVO+ARGUMENT ATIVOS/7809ef0d-5a4a-4c24-9a03-9db15e0bdacf?version=1.0

Koch IGV. Sobre a seleção do núcleo das formas nominais anafóricas na progressão referencial. In: Foltran MJ, Negri L, Oliveira RP, organizadores. Sentido e significação: em torno da obra de Rodolfo Ilari. São Paulo: Contexto; 2004a. p. 244-262.

Koch IGV. Introdução à lingüística textual. São Paulo: Martins Fontes; 2004b.

Koch IGV. Referenciação e orientação argumentativa. In: Koch IGV, Morato EM, Bentes AC, organizadores. Referenciação e discurso. São Paulo: Contexto; 2005. p. 33-52.

Koch IGV, Elias VM. Ler e Compreender: os sentidos do texto. São Paulo: Contexto; 2017.

Mondada L, Dubois D. Construção dos objetos-de-discurso e categorização: uma abordagem dos processos de referenciação. In: Cavalcante MM, Rodrigues BB, Ciulla A, organizadores.

Referenciação. São Paulo: Contexto; 2003. p. 17-52.

Oliveira RP, Basso RM. Arquitetura da conversação: teoria das implicaturas. São Paulo: Parábola Editorial; 2014.

Pereira KAPL. A contribuição de um analisador automático para a caracterização de gêneros textuais [trabalho de conclusão de curso]. Curitiba: Universidade Tecnológica Federal do Paraná; 2018. [citado 25 ago. 2020]. Disponível em: http://repositorio.roca.utfpr.edu.br/jspui/handle/1/11580.

Salvador A. Como escrever para o Enem: roteiro para uma redação nota 1.000. São Paulo: Contexto; 2013.

Silva NS. Análise textual mediada por ferramenta computacional: um estudo sobre redações estilo Enem. [trabalho de conclusão de curso]. Curitiba: Universidade Tecnológica Federal do Paraná; 2018. [citado 25 ago. 2020]. Disponível em: http://paginapessoal.utfpr.edu.br/bertucci/projetos-grupos-depesquisa-1/tcc-letras/TCC $\% 20-\% 20$ Nicolle $\% 20-\% 20$ corrigido.pdf/view

Tauil JC. A ocorrência da implicatura convencional no português brasileiro a partir de itens lexicais expressivos. [trabalho de conclusão de curso]. Curitiba: Universidade Tecnológica Federal do Paraná; 2017. [citado 13 mar. 2020] Disponível em: http://repositorio.roca.utfpr.edu.br/jspui/handle/1/11586

Val MGC. Redação escolar: um gênero textual? In: Garcez LHC, Corrêa VR, organizadores. Textos dissertativo-argumentativos: subsídios para a qualificação de avaliadores. Brasília: Instituto Nacional de Estudos e Pesquisas Educacionais Anísio Teixeira; 2017. p. 73-80.

Val MGC, Mendonça M. Coesão nominal: relacionar, categorizar e... argumentar. In: Garcez LHC, Corrêa VR, organizadores. Textos dissertativo-argumentativos: subsídios para a qualificação de avaliadores. Brasília: Instituto Nacional de Estudos e Pesquisas Educacionais Anísio Teixeira; 2017. p. 205-212. 